ARID International Journal of Social Sciences and Humanities (AIJSSH) VOL.4, NO.7, January 2022

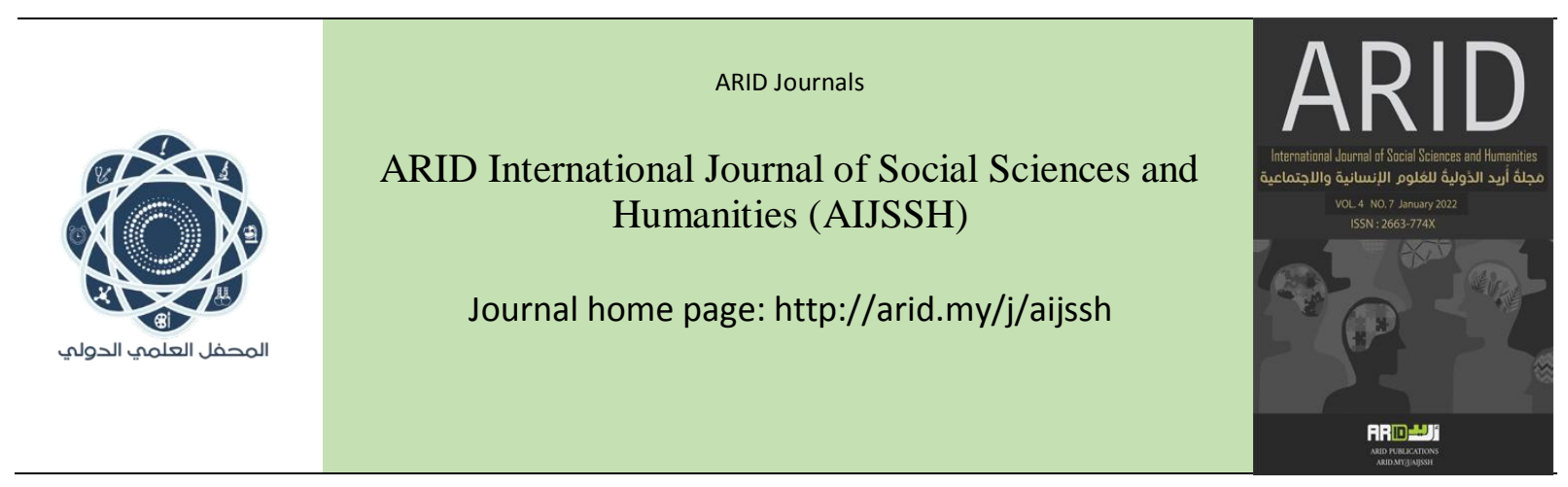

$$
\begin{aligned}
& \text { مَجلةُ أُريد الدَّوليةُ للعُلومِ الإنسانية والإجتماعية } \\
& \text { العدد السابع، البملد الرابع، كانون الثاني } 2022 \text { م }
\end{aligned}
$$

\title{
their relationship to moral values Personal traits of the prophet muhammed
}

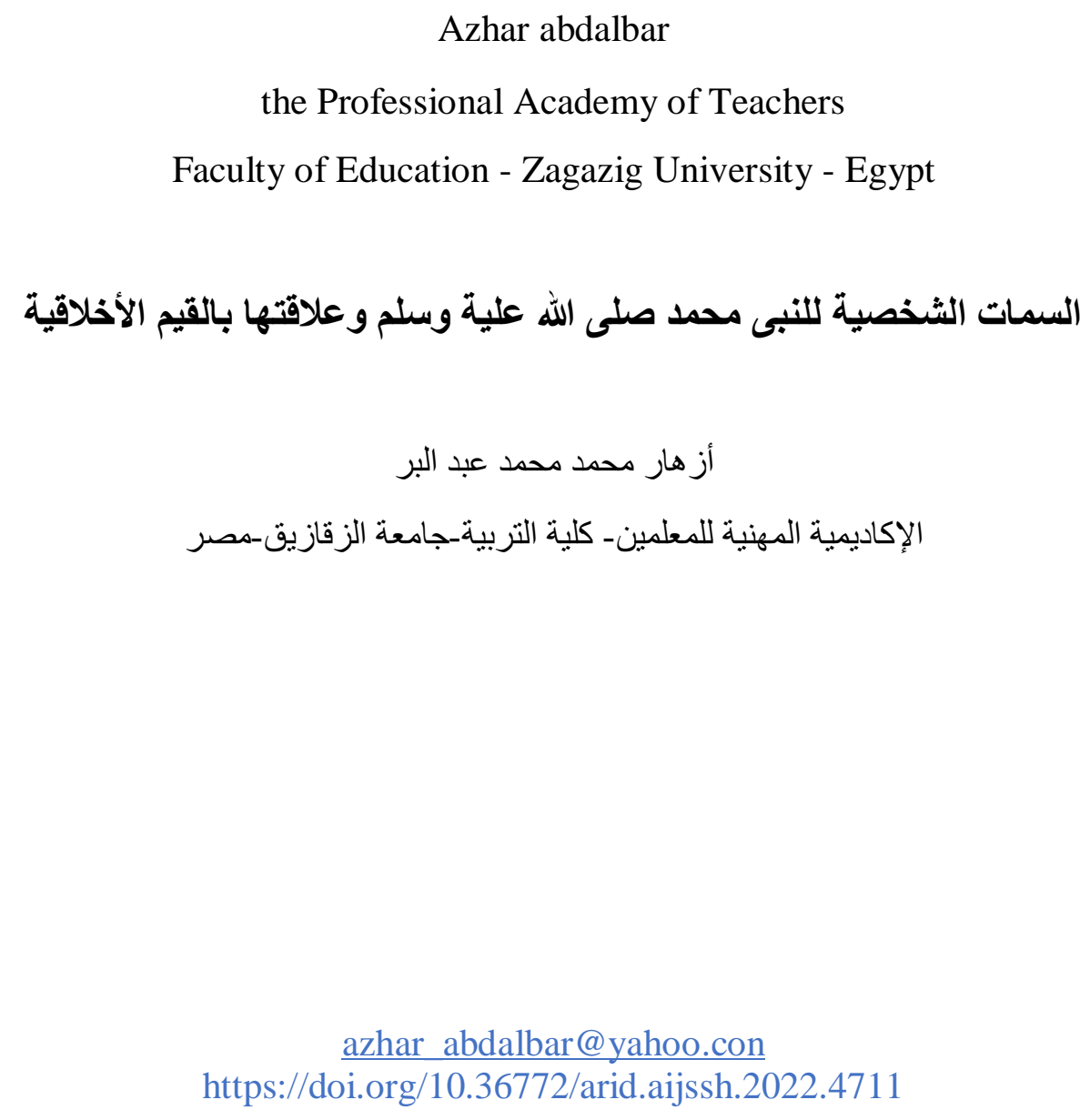




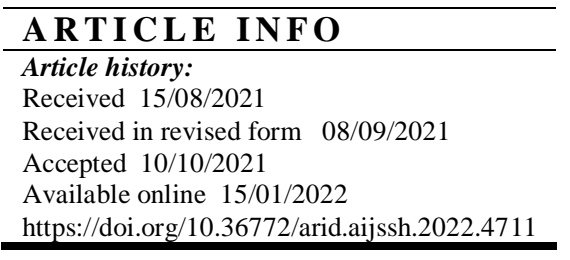

\begin{abstract}
The aim of the research is to identify the personal characteristics of the Prophet Muhammad, peace be upon him. The research sample consisted of 360 individuals from different spectrums in society. The descriptive and analytical method was used, and a questionnaire was prepared for the personal characteristics of the Prophet Muhammad (PBUH) and a questionnaire of the moral and human values in the contemporary world. : The personal characteristics of the Prophet Muhammad were as follows: The Prophet Muhammad, upon him be prayers and peace, was characterized by sincerity, honesty and generosity among his companions. He was characterized by humility, justice, forgiveness and pardon. He was characterized by sincerity in secret, openness and mercy for children. He was never afraid of anyone as long as he was right and his courage increased after the prophetic mission, from the human and moral values that have been agreed upon in the contemporary world: love and defense of the homeland, preservation of sacred places, love for school and appreciation of teachers, rationalization of the use of water and electricity, appreciation of scientific progress Generous hospitality, advising others, visiting patients, appreciating professions and respecting their owners, being kind to others, maintaining order, maintaining the law and respecting rights Child, animal welfare, justice, loyalty, patience, honesty, humility and respect for the rights of others, sympathy for the poor, selflessness, sincerity in work, tolerance for others, seeking lawful earnings, suppressing anger, kindness to animals, generosity, avoiding bad behaviors, Hide anger and do good deeds, love beauty, arts and inventions, appreciate scientific progress, provide advice to others, and the research also found that there is a positive and statistically significant relationship between the personal characteristics of the Prophet Muhammad, peace be upon him and between the human and moral values in the contemporary world.
\end{abstract}

Keywords: Personal traits - Prophet M - moral values 


\section{الملخص}

هدف البحث التعرف على السمات الشخصية للنبي محمد "صلى الله عليه وسلم " تكونت عينة البحث من 360 فرد من مختلف الأطياف

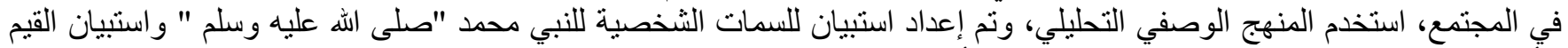

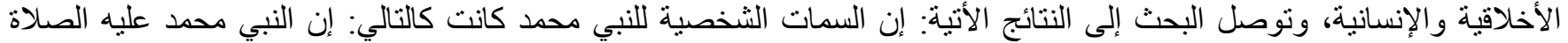

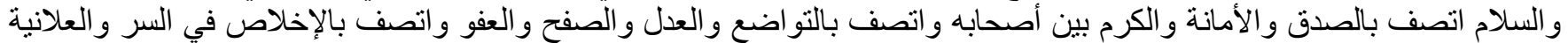

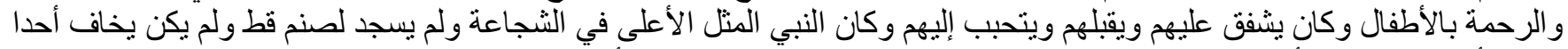

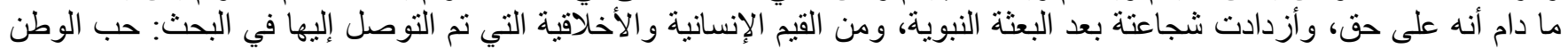

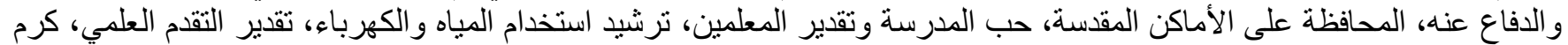

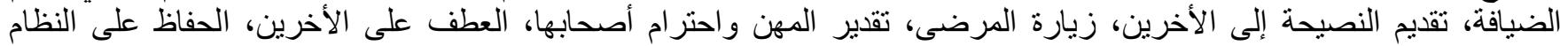

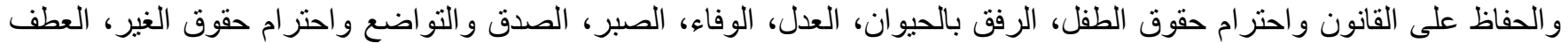

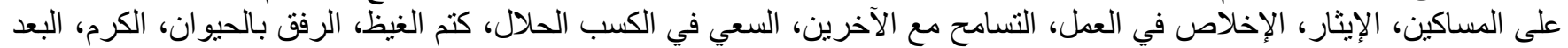

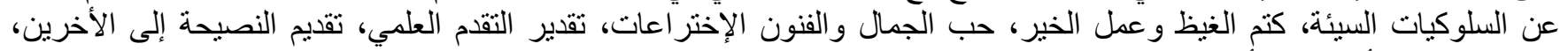

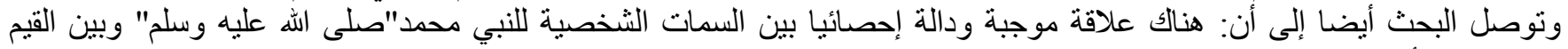
الإنسانية و الأخلاقية.

الكلمات المفتاحية : السمات الثخصية ـ النبي محمدـ القيم الأخلاقية. 


\section{مقدمة}

إن أعظم شخصية في التاريخ سيدنا محمد علية الصلاة والسلام فكان يمتلك التوازن النفسي والسلوكي في شخصيته، فعند دراسة شخصيته فنجد أن هنالك توازن دقيق بين معالمها مما لا يمكن أن تجده في أي بشر سواه وهذا التوازن يعد من أبرز دلائل نبوته ويتمثل في الكم الهائل من الشمائل ومحاسن الأخلاق التي اجتمعت في شخصيته عليه السلام، على نسق متعادل بحيث لا تطغى صفة على صفة و لاتوظف صفة في موقف لا تحتاجه و لا تليق به كان" صلى الله عليه وسلم "يسلك في التعليم أساليب تربوية، كان شخصية المعلم ويمتلك سمات شخصية كثيرة ما أروعها وأوقعها في النفوس، فتارة يضرب لهم الأمثلة، وتارة يستخدم لغة الإشارة الحسية كأن يحكي فعل شخص ما، وتارة يلغز لهم لينشطهم، وتارة يقص عليهم من أحو ال الأمم الماضية ليكون في ذلك عبرة لهم، وتارة يعلمه عمليا بأن يفعل هو ما يريد فيتابعون عليه، وتارة يسألهم عن الثيء ولم يسألو ا عنه ثم يجيبهم، وتارة يجيبهم على سؤ الهم بأكثر مما أر ادوا، وذلك من أجل فائدة عظيمة لهم، وغير ذلك كثير. و هذا كله مع الرأفة والرحمة واللين، وعذر الجاهل بجهله والاهتمام بتعليمه، ولم بقصر هذا على الرجال فقط بل النساء وبذل الجهد لهن من وقتة وجهده الكثير ، ويعتبر علماء التربية أن للقيم دورا في توجيه سلوك الفرد والجماعة فهي تقوده إلى إصدار الأحكام على الممارسات العملية التي يقوم بها، وهي الأساس السليم لبناء تربوي متميز كما أنها تسهم في تشكيل الكيان

$$
\text { النفسي للفرد [1]. }
$$

وبذلك يدرك علماء التربية بأهمية القيم لأنها: تساعد الفرد على تحمل المسؤلية تجاه حياته ليكون قادراً على تفهم كيانه الثخصي والإحساس بالرضا والتي يعتبر إحدى الركائز الإسلامية لضمان فعالية النشاط الإنساني، حيث تعمل على أن تكون المسؤلية بين الفرد و المجتمع تبادلية تضامنية متوازنة تحفظ للجماعة مصلحتها، وقوة تماسكها وللفرد تماسكه وحريته، وفي ضوء القيم الإسلامية يعيش الفرد في إطار قيمي يستمد منه دائما أنماط سلوكية سليمة، كما أن فوائد القيم في المجتمعات الإسلامية تساعد على التنبؤ بما سيكون عليه المجتمعات، فالقيم والأخلاقيات الحميدة هي الركيزة الأساسية التي تقوم عليها الحضار ات وأيضا تفي المجتمع من الأنانية المفرطة و النز اعات وتحفظ للمجتمع تماسكه وتحديد أهدافه ومبادئه الثابتة لممارسة حياة اجتماعية سليمة كما تعطي الأفر اد إمكانية تحقيق ما هو مطلوب منهم في إطار الرسالة الإسلامية على سلوك الفرد قولا وعملا كما تتعكس على الجماعة أيضا ويمكن تناول وظيفة القيم على المستوى الفردي وتتمنل وظيفة القيم، وتؤدي دورا مهما في تشكيل الثخصية الفردية أنها تعطى الفرد إمكانية أداء ما هو مطلوب منه وتمنحه القدرة على تحديد أهدافها في إطار معياري صحيح هو التكيف والتو افق الإيجابي وتحقيق الرضا عن نفسه لتجاوبه مع الجماعة في مبادئها و عقائدها الصحيحة أنها تحقق للفرد الأحساس بالأمان فهو يستعين بها على مو اجهة ضعف نفسه والتحديات التي تو اجهه في حياته تعطى للفرد فرصنه للتعبير عن نفسه [2] 
ولقد ظهرت مشكلة البحث: في محاولة بعض ضعاف النفوس الإساءة والتجرؤ على شخص الرسول العظيم إلا أن الثمس تظل ساطعة ونور ها نافذ مهما حاول الحاقدون حجب الحقيقة بافتراءاتهم و أكاذيبهم ومهما حملوا من حقد وظغينة وأبعاد عدائية تسعى ور اءها غايات لاتعرف النبل مطلقا ولقد انعكس إعجاب الأدباءغير المسلمين من العرب والغرب وحبهم الكبير للرسول "صلى الله عليه وسلم " وللدين الإسلامي على أعمالهم الأدبية شعرا ونثرا وبصورة صادقة قلما تجد لها نظير، وقد عرض البحث عن ملامح شخصية الرسول الأعظم في (البعد الأنساني - و الأخلافي) وقد حاول البحث إيصال صورة النبي الأعظم (صلى الله عليه وسلم ) إلى محبي الحقيقة ممن يتحرون الصدق من خلال أثخاص يدينون بديانة أخرى غير الإسلام أو قومية ولغة أخرى غير العربية. وتوضيح العلاقة الوثيقة الواضحة بين سمات النبي محمد و القيم الأخلاقية والإنسانية في العالم المعاصر. يمكن تلخيص مشكلة البحث الحالي في الإجابة على السؤال التالي: 1 - هل توجد علاقة بين السمات الثخصية للنبي محمد "صلى الله عليه وسلم" و القيم الأخلاقية ؟

- التعرف على العلاقة بين السمات الشخصية للنبي محمد"صلى الله عليه وسلم" والقيم الأخلاقية و الإنسانية.

- التعرف على صفات النبي محمد صلى الله عليه وسلم الخلقية. - التعرف على القيم الأخلاقية والإنسانية التي يجب أن تتوفر في العالم المعاصر.

تكمن أهمية البحث الحالي في الأهمية النظرية والتطبيقية من حيث الجانب النظري يتمركز البحث في المتغيرات النفسية الهامة التي نعتني بدر استها و إلقاء الضوء عليها و على خلفيتها النظرية، حيث يسعى البحث لدراسة السمات الثخصية لسيدنا محمد "صلى اله عليه وسلم "و علاقتها بالقيم الأخلاقية وما يترتب عليه، توضيح أن القيم الإنسانية والأخلاقية مستمدة من شخصية رسولنا الكريم محمد عليه أفضل الصلاة و أتم التسليم، ولتوضيح أنه قد تمثلت في شخص رسول الله "صلى الله عليه وسلم "أسمى مكارم الأخلاق، وتجمعت فيه كل الصفات الحميدة، فتعلق الناس به، وتركوا في حبه كل ما كان يربطهم بحياة الجاهلية الأولى، ولذا أثنى الله سبحانه وتعالى عليه بما لم يثن على نبي من أنبيائه، فقال نعالى :( وَإِنَّكَ لَعَلَى خُلُقِ عَظِيٍٍ ). و الأهمية النطبيقية في اتباع تعاليم النبي محمد واتباع ما جاء في سنته في تربية الأبناء وفي جميع أمور حياتنا. 
- حدود بشرية: تحدد البحث بـ ( 360) فرد من أفر اد المجتمع المصري بمختلف أطيافة منهم 150 سيدة و210 رجل. حدود زمنية: تم إجراء هذا البحث في العام 10/2020.

\section{مصطاح البحث:}

السمات الشخصية للنبي محمد"صلى الله عليه وسم": هي مجموعة من الصفات الخلقية التي يتصف بها رسولنا محمد "صلى الله عليه وسلم" وتتمثل في: (الصدق_الأمانة ـ الإخلاص الوفاء - التواضع - الثجاعة ـ الرحمة ـالعدل ـ الصفح و العفو ـ الكرم)

القيم الأخلاقية: هي التي تمثل الأحكام المعيارية التي يتم بمقتضاها تقييم سلوك الأفراد و الجماعات وتحديد ما هو مرغوب أو غير مرغوب و القيم تمثل أهداف معينة في الحياة يسعى الفرد إلى تحقيقها، فهي تمثل إطار ا مرجعياً يحدد سلوكيات الفرد لتحقيق هذه الأهداف والقيم التي يتبناها الفرد تكثف عن نفسها إما من خلال التعبير اللفظي و إما من خلال الأنشطة السلوكية التي تصدر عن الفرد في المواقف الحياتية. القيم الإنساتية: - ـ هي مجموعة من المبادئ التي تقوم عليها الحياة والتي يسعى الإنسان للتحلي بها، فهي التي تساعده على أن يحيا حياة كريمة و سليمة، فهي التي تحفظ لله كر امته وحريته، وتدعم حقوقه، وتحثه على القيام بواجباته، كما تحافظ على عرضه وماله و عقله، وتقوم القيم الإنسانية باعتبار الفرد إنسانًا قبل أي شيء، وبصفته عضوًا في جماعة، فمنها: (العمل، الحرية، العدل، العلم، الصدق، الأمانة، الإيثنار).

الإطار النظري: السمات الشخصية للنبي محمد: من صغره صلى الله عليه وسلم وعبقريته ظاهرة، وهمته عالية، والنفَس القيادي يلوح، فقد كان يوضع لجده عبد المطلب سرير بجنب الكعبة، فيُدفع عنه كل الصبيان، حتى يجيء رسول الله عليه الصلاة والسلام، فيحاولون دفعه، فيمنعهم جده عبد المطلب قائلا: (دعوا ابني هذا فإنه سيكون له شأن). و واستنبط أبو الفرج ابن الجوزي رحمه الله علو همنه من صباه، و عدم رضاه باليسير و القليل. [ 3] و اصطفاه الباري تعالى لرسالته، ورفعه دينا وعقلا وخلقا، فجمع ما بين منائر الوحي، وفطانه السلوك الاجتماعي، والذي جعل من سيرته مرجعا للعبقرية القبادية ( لقد كان لكم في رسول اله أسوة حسنة ) ومن أجل صفاته القيادية: الصدق والثجاعة، وقد اعترف بها 
المشركون، ولقبوه قبل البعثة ( بالصادق الأمين) وكانت إحدى علامات هرقل الرومي في الاستدلال على نبوته ( هل كُنتُ تتهمونه بالكذب) فقال: لا، فقلت: ما كان ليذر الكذب على الناس ويكذب على اله. [4 ]

و أما الثجاعة: فكانت شجاعته حاضر في كل المو اقف، ويكفي قول علي رضي الله عنه ( كنّا إذا اشتد بِنَا البأس اتقينا برسول الله صلى الله عليه وسلم ) و التروي في اتخاذ القرارات والدليل أن الأنصار لما انتهوا من عقد بيعة العقبة الثانية قالوا: يا رسول الله، إن شئت لنميلنّ على أهل منىً غداً بأسيافنا، فقال صلى الله عليه وسلم: (لم نؤمر بذلك، ولكن ارجعوا إلى رحالكم ). إثر الك الأمة و الأتباع في القرارات و مشاورنهم على الدوام (أنثيروا علي أيها الناس) رددها في مواطن مختلفة كبدر وأحد، تحقيقا للنهج القر آني (وشاور هم في الأمر ) سورة آل عمران. واستكمالا لنهج المجتمع المسلم (وأمر هم شورى بينهم ) سورة الثورى.[5] بل ذللك كان كثير اوطبعةً له، قال أبو هريرة رضي الله عنه (ما رأيت أحدًا قط، كان أكثر مشورةً لأصحابه من رسول اله صلى اله عليه و على آله وصحبه وسلم) أخرجه أحمد في مسنده (19231) و عبدالرازق في مصنفه (19720)، وابن حبان في صحيحه (4872)، قال ابن حجر في فتح الباري (393/5): رجالة ثقات، إلا أنه منقطع.

التضحية والخدمات الاجتماعية معالم قيادية، أحرز ها المصطفى المختار من قبل البعثة، فلما عاد من حر اء، قال لزوجه خديجة رضي الله عنها: (لقد خشيت على نفسي "، فقالت: كلا و الله لا يخزيك الله أبداً، إنك لتصل الرحم، وتَحمل الكَّل، وتُكسب المعدوم، وتَقَري الضيف، وتعين على نوائب الحق ): جزء من حديث أخرجة البخاري في صحيحة رقم 6982 وكان يفتح باب الحوار و المر اجعة كما في اختبار موضع بدر، وحكم الأسرى، وعاد إلى رأي الحُباب بن المنذر رضي الله عنه: إن هذا ليس بمنزل.

بُعد نظره العجيب، كما صنع في (صلح الحديية) من الصبر وقبول غبن الصلح ومضضه، ليتفرغ للاعوة وإظهار سماحة الإسلام، وفضح غرور القرشيين و عدم صلاحيتهم للإشر اف على مكة وحرمها، وكذلك تركه لقتل المنافقين برغم استحقاقهم (لئلا يتحدث العرب أن محمدا يقتل أصحابه) كما في الصحيحين.

وكان في خدمة الناس ومشاركتهم الأعمال و المهام : كما شارك في بناء المسجد وحفر الخندق بر غم المتاعب والجوع، ولكنه رسخ في عقولهم فضيلة العمل و التو اضع واحتمال الثدائد، وسيد القوم خادمهم، كما ينقل.[6] 
ـ تهيئة الثباب و الصف الثاني و القواعد البديلة: كما حصل من تربية ابن عباس على العلم، وأسامة للقيادة، ومصعب للاعوة، وترك مهاجري الحبشة إلى سنة (У) للهجرة للأحوال الطارئة. ومع بأسه وحزمه لم تناً عنه صفات الرحمة و العفو: في مظانه التاريخية، قال تعالى (بالمؤمنين رؤوف رحيم) سورة التوبة، ولما فتح مكة ذلك الفتح الأعظم، عفا وسامح وقال: (اذهبوا فأنتم الطلقاء ).[7] ومن صفاته: إعداد الرجال وصناعة الأبطال كما صنع في دار الأرقم بن أبي الأرقم، وخلّص جلسائه كما قال علي رضي الله عنه: ( كنت أكثر أسمع رسول الله صلى الله عليه وسلم يقول: جئت أنا وأبو بكر وعمر ودخلت أناو أبو بكر وعمر..) :اخرجة البخاري في صحيحه (3507,3515 ) وابن ماجه في سنته (98) و أحمد في المسند (884) والحاكم في المستدرك (4401) و النسائي في الكبرى (6890) و أبو حنيفة في مسنده برواية أبي نعيم (4) و عبد الله بن المبارك في مسنده(255) وأحمد في فضائل الصحابة (307) وابن شبه في ناريخ المدينة (1503) و البزار في مسنده (428) و(332) والأجرى في الشريعة (1301) و اللاكائي في شرح أصول اعتقاد أهل السنة و الجماعة (2002) و أبو نعيم الأصبهاني في تنبيت الأمامة وترتيب الخلافة (67). ومن صفاته: الثبات على مبادئه ودعوته، برغم العروض المقدمة، والإغراءات السالبة، والتي وضعتها قريش ومن خلال نائبها عتبة بن ربيعة (با ابن أخي إن كنت إنما تريد بما جئت به من هذا الأمر، مالا جمعنا للك من أمو النا حتى تكون أكثرنا مالا، و إن كنت تريد به شرفا سودنالك علينا حتى لا نقطع أمراً دونك...) فما زاد رسول الله على الإنصات وتلاوة صدر سورة فصلت التي قطعت عنقه، وقرّعت أذنه ومنها: حزمه الإداري، مثل ما صنع مع الثاعر الهجاء أبي عزة الجُمحي، وكان عفا عنه في بدر، فعاد في أحد وأسره، فأمر به وقُتل، وقال: (لا ترجع إلى مكة، فتمسح عارضيك، وتقول: خدعت محمدا مرنين، لا يُلاّغ المؤمن من جحر واحدٍ مرتين ).[8] و هو ليّن رفيق وقت الرفق، شديد متين وقد الثُدة والحسم: يحمي الضعفاء، ويساعد الموالي و المساكين، ويقول (إخو انكم خوَلكم..) أخرجة البخاري (30) ومسلم (1661) كما في الصحيح ، وتأتيه الجارية من نساء المدينة فيقضي حاجنها حيث شاءت.عدالته الفذة، و عيشه الزا هد الفريد، وحرصه على محاسبة أقاربه (لو أن فاطمة بنت محمد سرقت لقطعت يدها ).الحرص على التجميع ونبذ الخلاف و التقطيع، مما يزينه رواة الأخبار و الثائعات.]9]

وقد صح قوله:( يد الله مع الجماعة) وقوله:( إن الثيطان قد يئس أن يعبده المصلون في جزيرة العرب، ولكن في التحريش بينهم)

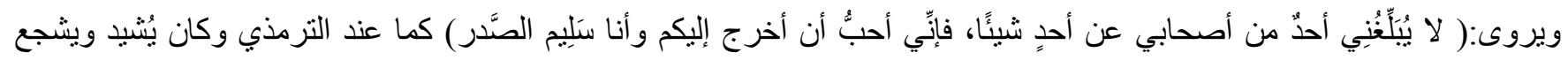
ويرفع المعنويات، حتى يجعل من أتباعه قوة متلاحمة، وفئة ترهبها الخصوم، فيريهم في بدر مصار ع القوم، وفي الخندق يبشر هم بالعاقبة و الفتوحات، ويقول (الآن نغزوهم و لا يغزوننا نحن نسير إليهم ). وهو الصبور القنوع الحكيم، الذي يشتري الأقوام بالدنيا ولعاعتها، ويرسخ مبادئ آخرين حينما يكلهم لإيمانهم، كما فعل في حنين، فأعطى المؤلفة قلوبهم عطاءَ من لا يخشى الفقر، قَالَ أَنَسُ رضي الله عنه: 


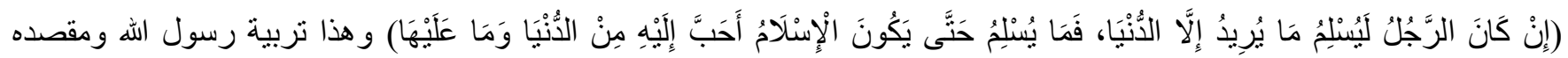
الإداري والاستر اتيجي. [ 10 ]

و هو القائد البارز للناس: فلا حجاب ولا ابتعاد، وبابه مفتوح لكل طارق، قاض للحوائج ومجيب للسائلين، قال جرير رضي الله عنه( ما حجني رسول منذ أسلمت، وما رآني إلا تبسم في وجهي ). ويستطيع كل أعرابي، وصغير وكبير الوصول إليه، ومثل ذاك مع ما فيه من متاعب، إلا إنه يصل إلى الأفئدة بلا استئذان (و إنك لعلى خلق عظيم) سورة القلم. 11 ] وهو الثخصية المعتدلة، التي لا تغضب على كل حال، ولكن في مواضعه الصحيحة، كانتهالك الحرمات، وقال لرجل (لا تغضب) وصح قوله:( ليس الثُديد بالصُُرَعة ولكن الثُديد الذي يملك نفسه عند الغضب. ولا تز ال سيرته عليه الصلاة والسلام تغزر بالمعالم القيادية و السمات الر ائعة فقها وشأنا وسياسة و إدارة. [ 12 ]

\section{القيم الأخلاقية:}

وتمثل القيم مركز اً مهماً في توجيه العملية التربوية، لما لها من أهمية كبرى في حياة الفرد، كما تلعب القيم دوراً مهماً في تكوين شخصية الفرد من خلال تحليل سلوكه وفهمه وتعد القيم الأخلاقية من أهم مجالات القيم، لما لها من دور بارز في تحديد معالم الثخصية، كيف لا وقدوتنا في ذلك محمد صلى الله عليه وسلم معلم الأخلاق الأول القائل: (إنما بعثت لأتم مكارم الأخلاق)، وقد أثنى عليه ربه بقوله

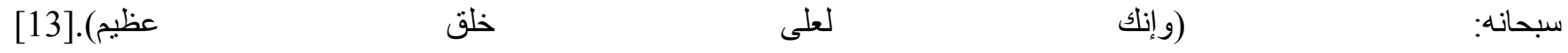
وتعمل القيم الأخلاقية بشكل دائم على تأهيل المسلم كي يكون إيجابياً وفعالاً في الحياة، ومن ذلك إسهامه المتكرر في عملية البناء والتنمية الحديثة والقيم بمعناها الاصطلاحي الثامل تعني (مجموعة معايير وتتكون لدى الفرد تمكنه من تحقيق هدفه في الحياة) وقيل هي (مجمو عة المبادئ و القو اعد و المثل العليا التي يتخذ منا الناس ميز اناً يزنون بها أعمالهم، ويحكمون بها على تصر فاتهم المادية و المعنوية). و علاقة القيم بالتنمية علاقة وثيقة، فالتنمية تقوم على مجموعة من القيم أهمها: القيم النظرية وهي تعنى بالمعرفة واكتشاف الحقيقة و التعرف على حقائق الأشياء. القيم الأخلاقية: وهي مجال هذه الدراسة وهي من أهم القيم الإسلامية المؤثرة في حياة الفرد، لكونها تحدد نوع تعامله مع الغير، وتغرس المحبة في نفوس الآخرين، وتعمل على كسب القدوة الحسنة، والقصد الحسن مما له أثر على نجاح العملية التنموية .ومن هنا يمكن تعريف (القيم الأخلاقية) بأنها: المبادئ والمعايير التي توجه الفرد وتضبط سلوكه في الحياة، ويتحدد بموجبها مدى فاعليته في المجتمع. وقد اهتم الإسلام بالقيم الأخلاقية كعنصر أساس في التنمية، ويتمثل ذلك بدعوة المؤمنين إلى مكارم الأخلاق لما في ذلك من رفعة و علو منزلة ومن الآثار الحسنة لمكارم الأخلاق ما يلي - تعمل على تكوين البناء الوجداني للإنسان، وتشعره بدوره في الحياة .تساعد القيم الأخلاقية المجتمع على مواجهة التغيرات التي تحدث فيه مما يعين على اختيار الحلول المناسبة التي تحفظ على 
ـ تعمل على سرعة الإنجاز والجودة ببب الإخلاص والأمانة وهذا يحقق تقدماً ملموساً في التنمية .فالتعليم أياً كان نوعه هو محور التنمية، إذ لا يمكن لأي مجال من مجالات التتمية أن يتم ويؤدي دوره إلا بدراسة مسبقة تعطي تصوراً كاملاً عن فعالية التنفيذ وما قد يطر أ عليه من سلبيات يمكن تلافيها قبل وقو عها لضمان سلامة العملية التنموية فعلى سبيل المثال: التعليم الثانوي يعد من أصعب مراحل التعليم نظر اً للمستوى العمري للطلاب والطالبات، والذي يمر بمرحلة حرجة من مراحل العمر وهي مرحلة المراهقة، ومن المعلوم أن نجاح العملية التعليمية في هذه المرحلة يعني نجاح ما بعدها، وهذا يتطلب الرجوع إلى عامل القيم الأخلاقية التي يجب أن يتحلى بها المعلم في المقام الأول لأنه هو القدوة لطلابه. فالقيم يجب أن تكون مو اكبة للعملية التعليمية منذ البداية لا تتفك عنها، حتى نضمن النتائج الطيبة لأبنائنا وبناتنا الذين هم عماد المستقبل لافع عجلة التنمية. [15 ]

\section{تعريف القيم الإنسانية:}

القيمة هي الثيء الثمين لدى الأنسان و الذي يسعى إلى امتلاكه و الاستحو اذ عليه، وأما القيمة الإنسانية فهي المبادئ الإنسانية التي جاءت بها كل الأديان، وركزت عليها جميع الحضارات، وأجمع عليها المفكرون والفلاسفة، وأكدها العقل البشري وأيدتها الفطرة البشرية

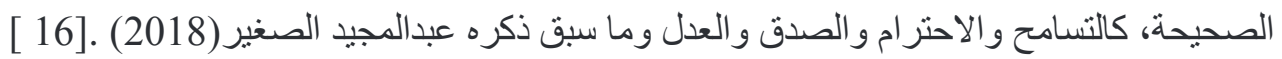

\section{أهمية القيم الإنسانية:}

قد جاءت القيم لتنظيم حياة البشر وتحقيق السعادة والسلام والرخاء، و هذا ما سنعرفه عن أهمية القيم الإنسانية: تعمل القيم الإنسانية على القى توحيد الأمم وجعلهم أمة واحدة عن طريق ترسيخ الاحترام والتفاهم وقبول الأخر ونبذ الصراعات التي تقوم على أساس التمييز عن طريق اللون والجنس والعرق فتعمل القيم الأنسانية على جميع الاختلافات والحث على رؤيتة أو جهة التشابه لتعميق الاتصال بين [17] تزيد القيم الإنسانية من احتر ام الفرد لذاتة فحيثما يتلقى الفرد المعاملة الحسنة والاحتر ام من حوله ويرى تقدير الدوره واحتر اما لكر امته، فإن هذا يزيد من احتر امه لنفسه و إحساسه بالإنتماء للمجتمع الذي يعيش فيه ومن ضمن محاسن القيم الإنسانية وأهميتها وهو زيادة دافعية الأفر اد على العمل و الإنتاج لما تحققة من زيادة تقدير الذات لدى الأفراد فيزيد ذلك من انتاجيتهم وحبهم للعمل، تعمل القيم الإنسانية على تقوية أواصر الإخاء والمحبة بين جميع أفراد المجتمع وتجعهم يعيشون في عالم مليء بالحب والسلام ومر اعاة مشاعر الآخر وظروفه و احتياجاته وتزداد أعمال الخير مع وجود القيم الإنسانية في المجتمع من مساعدة الفقر اء وقضاء حوائج الآخر والمواساة و الإيثار و غير ها من الصفات الجميلة التي نحب أن نر اها بمجتمعاتنا. [18] 
إن القيم تجعل الإنسان يحيا حياة سليمة وتعمل على إصلاحه نفسيًا وعقليًا، وترشده إلى أعمال الخير والإحسان من أهمية القيم الإنسانية و أكثر ها حاجة في مجتمعاتنا هو ضبط سلوكيات الفرد و أفعاله، و إبعاده عن أعمال الثر كالقتل و السرقة و الغش، وتساعده على التحكم في شهواته، فهي تجعل الإنسان إنسانًا قبل أي شيء. [19]

\section{خصائص القيم الأنسانية: تتصف القيم الإنسانية بمجمو عة من الخصائص، و نذكر ها فيما يلي: - إنها انسانية، أي تختص بالإنسان دون غبره من الكائنات.}

- إنها ذاتية، فعلى الرغم من عموميتها واتفاق المجتمعات عليها إلا أن شعور الفرد بها يختلف من إنسان إلى آخر وطريقة أدائة لها وطريقة إحساسة بها تختلف بين الأشخاص.

- إنها نسبية، فالقيم تختلف من زمان لزمان آخر، ومن مكان لآخر، حتى في المجتمع الواحد تجد ما يصلح في مكان لا يصلح في مكان غيره.

ـ قابليتها للقياس يمكننا قياس القيم من خلال الملاحظة و الاستبيانات، و هذا ما تهتم به علوم النفس و الاجتماع و الفلسفة.

ـ إنها متغيرة فالقيم تتغير من عصر إلى عصر، ومن وقتٍ لآخر، و لا تثبت على وتيرة واحدة وذلك في القيم الاقتصادية أو الجمالية أو السياسية أو النظرية أو الاجتماعية، أما القيم الأخلاقية و الدينية فهي قيم ثابتة لاتتغير مع تغير الزمان أو المكان.

ترى الباحثة أنها متغيرة وليست ثابته نتيجة لتفاعل الإنسان مع بيئتة وتغيرات الوسط المحيط وهي غير وراثية ومكتسبة من خلال البيئة المحيطة والمجتمع. - إنها مكتسبة فالقيم يكتسبها الإنسان من المجتمع الذي يعيش فيه، ولا يرثها.

- إنها متر ابطة فالقيم يكمل بعضها البعض، فلا تجد قيمة بمفردها، غالبًا ما يتحد الصدق والأمانة، والخير والإيثار، ويترابطو ا جميعًا.] [ 20 ] إجراءات البحث:

منهج البحث: استخدمت الباحثة المنهج الوصفي التحليلي في جمع البيانات والمعلومات عن طريق اسنبانه تم تصميمها لهذا الغرض ومن ثم تحليل البيانات و المعطيات المناسبة واستخلاص النتائج و التعليق عليها. 


\section{عينة البحث:}

تحدد البحث بـ ( 360) فرد من أفر اد المجتمع المصري بمختلف أطيافة منهم 150 سيدة و210 رجل.

$$
\text { أدوات البحث وخصائصها السيكومنرية. }
$$

استبيان السمات الثخصية للنبي محمد "صلى الله عليه وسلم".

هي استبانة مكونة من محور واحد فقط: و هو السمات الخلقية للنبي محمد "صلى الله علية وسلم" : ومن أجل التأكد من صدق أداة البحث تم عرضها على مجموعة من المحكمين في كلية التربية وقد أبدى السادة المحكمين وجهة نظر هم وملاحظتهم وتم الأخذ بها. وقد قامت الباحثة بحساب الصدق و الثبات: ـ الصدق : تم حساب الصدق بالطرق الآتية :

ـصدق المحكمين: وتم التحقق من صدق الاستبيان بعرضه على مجموعة من المحكمين و المتخصصين في علم النفس التربوي و عددهم عشرة محكمين وكانت نسبة الاتفاق عليها 96\% على أن الاستبانة صالحة لاستخدامها في هذا البحث. ـ صدق الاتساق الداخلي: تم حساب الاتساق الداخلي لكل عبارة من عبار ات المقياس.

جدول(1): يوضح معاملات الارتباط ومستوى الدلالة لكل عبارة من استبيان السمات الشخصية للنبي محمد "صلى الله عليه و سلم"

\begin{tabular}{|c|c|c|c|c|c|}
\hline مستوى الدلالة & معامل الارتباط & رقم العبارة & مستوى & معامل الارتباط & رقم العبارة \\
\hline 0.01 & 0.87 & 6 & 0.01 & 0.63 & 1 \\
\hline 0.01 & 0.86 & 7 & 0.01 & 0.45 & 2 \\
\hline 0.01 & 0.75 & 8 & 0.01 & 0.71 & 3 \\
\hline 0.01 & 0.76 & 9 & 0.01 & 0.65 & 4 \\
\hline 0.01 & 0.72 & 10 & 0.01 & 0.61 & 5 \\
\hline
\end{tabular}

يتضح من الجدول السابق أن معاملات الارنباط بين عبار ات الاستبيان و البعد كلها معاملات دالة مما يدل على صدق الاستبيان وصلاحيتة للقياس من لإن تم حساب الثبات عن طريق معامل الثبات بطريقة التجزئة النصفية لـ سبيرمان- بر اون Spearman-Brown، و الجدول [1] يوضح ذلك: جدول(2): حساب الثبات لاستبيان السمات الثخصية للنبي محمد "صلى الله عليه وسلم

\begin{tabular}{|c|c|c|}
\hline معامل ثبات التجزئة النصفية & عدد المفردات & الأبعاد \\
\hline .66 & 10 & محمد (صلى الله عليه وسلم ) السمبية الخلقية للنبي \\
\hline
\end{tabular}


- يتضح من الجدول (2) أن معاملات الثبات بلغت ( 66. ) و هي معاملات ثبات مرتفعة ودالة إحصائيًا مما يسمح باستخدام هذا

$$
\text { الاستبيان في الدر اسة الحالية. }
$$

الاتساق الداخلي بين البعد و الدرجة الكلية للمقياس:

تم حساب الاتساق الداخلي بين البعد والدرجة الكلية الاستبيان:عن طريق معاملات الارتباط بين درجة البعد والدرجة الكلية استبيان السمات الشخصية للنبي محمد (صلى الله عليه وسلم) والدرجة الكلية الاستبيان و الجدول التالي يوضح ذلك:

جدول(3): معاملات الارتباط للاستبيان السمات الثخصية للنبي محمد"صلى الله عليه وسلم"

\begin{tabular}{|c|c|c|c|}
\hline مستوى الدلالة & الارتباط معامل & الأبعاد & r \\
\hline 0.01 & $* * .57$ & السمات الثخصية الخلقية للنبي محمد (صلى الله عليه وسلم) & $\overline{11}$ \\
\hline 0.01 & $* * .63$ & الدرجة الكلية & 2 \\
\hline
\end{tabular}

ويتضح من جدول (3) أن قيم معاملات الارتباط مرتفعة ودالة عند مستوى (0.01) مما يدل على وجود اتساق داخلي مرتفع

بين البعد والدرجة الكلية الاستبيان، ومن ثم فابن البعد يتمتع بدرجة عالية من الاتساق الداخلي، مما يدل على صدق وثبات

المقياس وصلاحيتة في قياس السمات الشخصية للنبي محمد (صلى الله عليه وسلم).

\section{2 - استبيان القيم الاخلاقية والإنسانية:}

هي استبانة مكونة من محورين (القيم الأخلاقيةـ القيم الإنسانية) يتكون الاستبيان من (37) عبارة موز عة على بعدين، يتكون كل بعد من (17) عبارة ويكون الاستجابة على الفقرات وفقا لتدرج مقياس ليكرت الخماسي (ينطبق بدرجة كبيرة جدا-ينطبق بدرجة كبيرة-ينطبق بدرجة متوسطة سيطبق بدرجة صغيرة-لاينطبق تماما). وتكون الدرجات (5-4-3-1-1) ومن أجل التأكد من صدق أداة البحث تم عرضها على مجموعة من المحكمين في كلية التربية وقد أبدى السادة المحكمين وجهة نظر هم وملاحظتهم وتم الأخذ بها. وقد قامت الباحثة بحساب الصدق والثبات: ـالصدق: تم حساب الصدق بالطرق الآتية:

صدق المحكين: وتم التحقق من صدق الاستبيان بعرضه على مجموعة من المحكمين والمتخصصين في علم النفس التربوي وعددهم عشرة محكمين وكانت نسبة الاتفاق عليها 99\% على أن الاستبانة صالحة لاستخدامها في هذا البحث. 
صدق الاتساق الداخلي: تم حساب الاتساق الداخلي للعبار ات وذلك بايجاد معاملات الارتباط بين الدرجات التي حصل عليها المفحوص في كل عبارة من عبار ات الاستبانة والدرجة على البعد.

ثبات الاستبيان: تم حساب الثبات عن طريق معامل الثبات بطريقة التجزئة النصفية لـ سبيرمان- بر اون Spearman-Brown، و الجدول (4) يوضح ذلك: الاتساق الداخلى بين الأبعاد والدرجة الكلية للمقياس: تم حساب الاتساق الداخلي بين الأبعاد والدرجة الكلية الاستبيان:عن طريق معاملات الارنباط بين درجة كل بعد من استبيان القيم الأخلاقية والإنسانية و الدرجة الكلية الاستبيان و الجدول النالي يوضح ذلك:

جدول(4): معاملات الارتباط بين درجة كل بعد من استبيان " القيم الإخلاقية والإنساتية " والدرجة الكلية للاستبيان

\begin{tabular}{|c|c|c|c|}
\hline الدلالة & الارتباط معامل & الأبعاد & 5 \\
\hline 0.01 & $* * .64$ & البعد الأول: القيم الأخلاقية & 1 \\
\hline 0.01 & $* * .55$ & البعد الثاني: القيم الإنسانية & 2 \\
\hline 0.01 & $* * .58$ & الدرجة الكلية & 3 \\
\hline
\end{tabular}

ويتضح من جدول (4) أن قيم معاملات الارتباط مرتفعة ودالة عند مستوى (0.01) مما يدل على وجود اتساق داخلي مرتفع لأبعاد الاستبيان، ومن ثم فإن أبعاد الاستبيان تتمتع بدرجة عالية من الاتساق الداخلي مما بدل على صدق وثبات الاستبيان وصلاحيته في قياس القيم الأخلاقية والإنسانية. حساب الثبات:

تم حساب ثبات الأبعاد الفرعية لمقياس التنمر المدرسي بطريقتين: الأولى عن طريق معامل ألفا لـ كرونباخ، و الثانية عن طريق معامل الثبات بطريقة التجزئة النصفية لـ سبيرمان- براون Spearman-Brown ، فوُجد أن معاملات ثبات الأبعاد الفر عية للمقياس بالطريقتين مرتفعة، مما يدل على ثبات الأبعاد الفرعية للمقياس، كما بالجدول التالي: 


\section{جدول(5): معاملات ثبات الأبعاد القرعية والثبات الكلي استبيان القيم الأخلاقية والإنسانية:}

\begin{tabular}{|c|c|c|c|c|}
\hline \multicolumn{2}{|l|}{ معامل الثبات } & \multirow{2}{*}{ العبار ات } & \multirow[b]{2}{*}{ الأبعاد الفرعية } & \multirow[b]{2}{*}{ p } \\
\hline معامل الثبات بطريقة التجزئة النصفية لـ & لـ لـ كرونباخ ألفا & & & \\
\hline 0.77 & .84 & 10 & البعد الاول: القيم الأخلاقية & 1 \\
\hline 0.88 & 0.82 & 10 & البعد الثاني: القيم الإنسانية & 2 \\
\hline \multicolumn{2}{|l|}{.88} & 30 & الثبات الكلي & \\
\hline
\end{tabular}

إن جميع معاملات الارتباط بين درجة كل عبارة من العبار ات والدرجة الكلية للبُعد الفرعي الذي تنتمي إليه العبارة (في حالة حذف درجة العبارة من الدرجة الكلية للبُعد الفرعي الذي تنتمي إليه) دالة إحصائيًا عند مستوى (0.01) أو (0.05) مما يدل على ثبات جميع عبار ات المقياس، من خلال ما سبب يتضح صدق وثبات المقياس وصلاحيتة لقياس القيم الأخلاقية والإنسانبة .

\section{نتائج البحث ومناقشتنها:

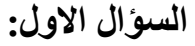

للإجابة على السؤال الأول الذي ينص على: ما هي السمات الثخصية للنبي محمد (صلى الله عليه وسلم) تم استخدام التكرارات والنسب

$$
\text { المؤية و الجدول(6) التالي يوضح ذللك: }
$$

\begin{tabular}{|c|c|c|c|}
\hline$\gamma$ & نعم & السمات الشخصية للنبي محمد (صلى الله عليه وسلم) & ? \\
\hline$\% 1$ & $\% 99$ & كان النبي محمد علية الصلاة والسلام يتصف بالصدق & 1 \\
\hline$\% 1$ & $\% 99$ & 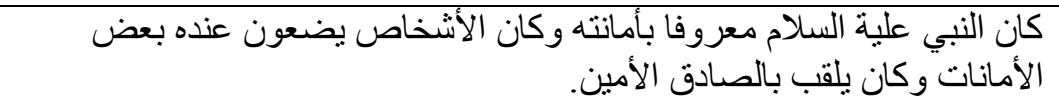 & 2 \\
\hline$\% 0$ & $\% 100$ & كان النبي محمد صلى الله علية وسلم يتصف بالإخلاص في السر و العلانية & 3 \\
\hline$\% 0$ & $\% 100$ & كان النبي محمد عليه السلام وفي لأصحابة ولزوجتة خديجة بعد وفاتها & 4 \\
\hline$\% 1$ & $\% 99$ & 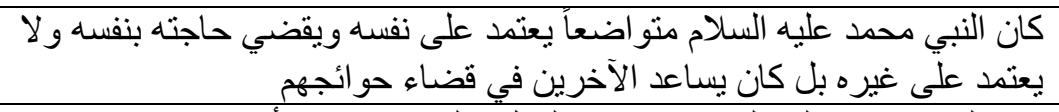 & 5 \\
\hline$\% 1$ & $\% 99$ & كان النبي محمد عليه السلام يتصف بالعدل و المساو اة بين الأفر اد & 6 \\
\hline$\% 0$ & $\% 100$ & ويقبله النبي محمد عليه السلام رحيما بأمته وكان رحيما بالأطفال يشفق عليهم & 7 \\
\hline$\% 1$ & $\% 99$ & الخدم والعمال مانح من صفات النبي محمد وقد بلغ درجة عالية من الصفح و العفو مع & 8 \\
\hline$\% 1$ & $\% 99$ & 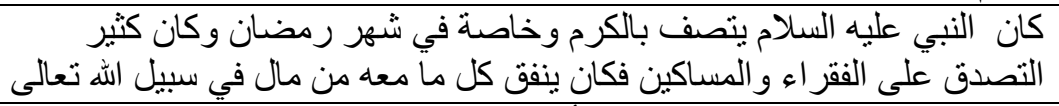 & 9 \\
\hline$\% 0$ & $\% 100$ & 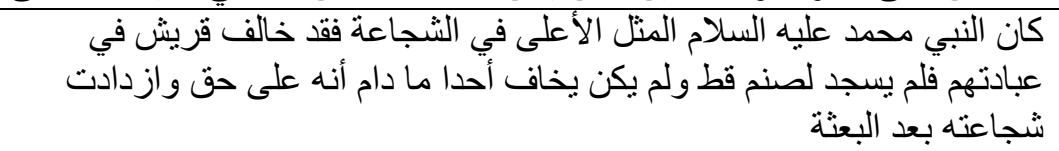 & 10 \\
\hline
\end{tabular}


يتضح من الجدول السابق الآتى: أن 99\% من عينة البحث اتفقو على أن النبي محمد عليه الصلاة والسلام اتصف بالصدق وكذلك الأمانة و الكرم بين أصحابه وكذلك اتصف بالتو اضع و العدل و الصفح و العفو.

وكذلك اتفق 100\% من عينة البحث على أن النبي محمد صلى الله عليه وسلم اتصف بالإخلاص في السر والعلانية وكذلك الرحمة بالأطفال وكان يشفق عليه ويقبلهم ويتحبب إليهم، وكان النبي المثل الأعلى في الثجاعة ولم يسجد لصنم قط ولم يكن يخاف أحدا ما دام أنه على حق وازدادت شجاعته بعد البعثة واتضح ذلك من خلال بحث رفل الطائي وذكريات المبارك(2015) أن الحديث عن صفات النبي الأعظم محمد (صلى الله عليه وسلم) وملامح شخصيته لم تترك أثرها البالغ في نفوس المسلمين فقط بل وغير المسلمين كذلك من العرب و غير العرب فقد كان كتابا مفتوحا للعالم بأسره ينهل من عظمته وتميزه، وما منحه الإسلام من شمولية واسعة للانفتاح على الكون بأكمله و التزود من مناهله العذبة الصافية بما جسد من مبادىء عظيمة وبما حمل الرسول (محمد صلى الله عليه وسلم ) من إنسانية وخلق متكاملين، وما ضم تحت جناحيه من عطف وإحسان شمل الخلق بأكمله وإن حاول بعض ضعاف النفوس الإساءة والتجرؤ على شخص الرسول العظيم ( محمد صلى الله عليه وسلم) إلا أن الثمس تظل ساطعة ونور ها نافذ مهما حاول الحاقدون حجب الحقيقة بافتر اءاتهم و أكاذيبهم، ومهما حملوا من حقد وظغينة وأبعاد عدائية تسعى ور اهها غايات لا تعرف النبل مطلقا ولقد انعكس إعجاب الأدباء غير المسلمين من العرب والغرب وحبهم الكبير للرسول (صلى الله عليه وسلم) وللدين الإسلامي على أعمالهم الأدبية شعرا ونترا وبصورة صادقة قلما تجد لها نظير، وقد عرض البحث عن ملامح شخصية الرسول الأعظم عند الأدباء الغربيين في أبعاد أهمها (البعد الإنسانني و الأخلاقي - و البعد العقائدي، ومن أولئك الأدباء (جوته، تولوستوي، وبوشكين، وغير هم الكثير وقد حاول البحث إيصال صورة النبي الأعظم (صلى الله عليه وسلم ) إلى محبي الحقيقة ممن يتحرون الصدق من خلال أثخاص يدينون بديانة أخرى غير الإسلام أو قومية ولغة أخرى غير العربية .

\section{السؤال الثاني:}

لإجابة السؤال الثاني الذي ينص على: ما هي القيم الأخلاقية والإنسانية التي يجب أن يتحلى بها الأفر اد في العالم المعاصر؟ تم استخدام التكر ارات و النسب المؤية ويتضح ذلك في الجدول(7) التالي: 


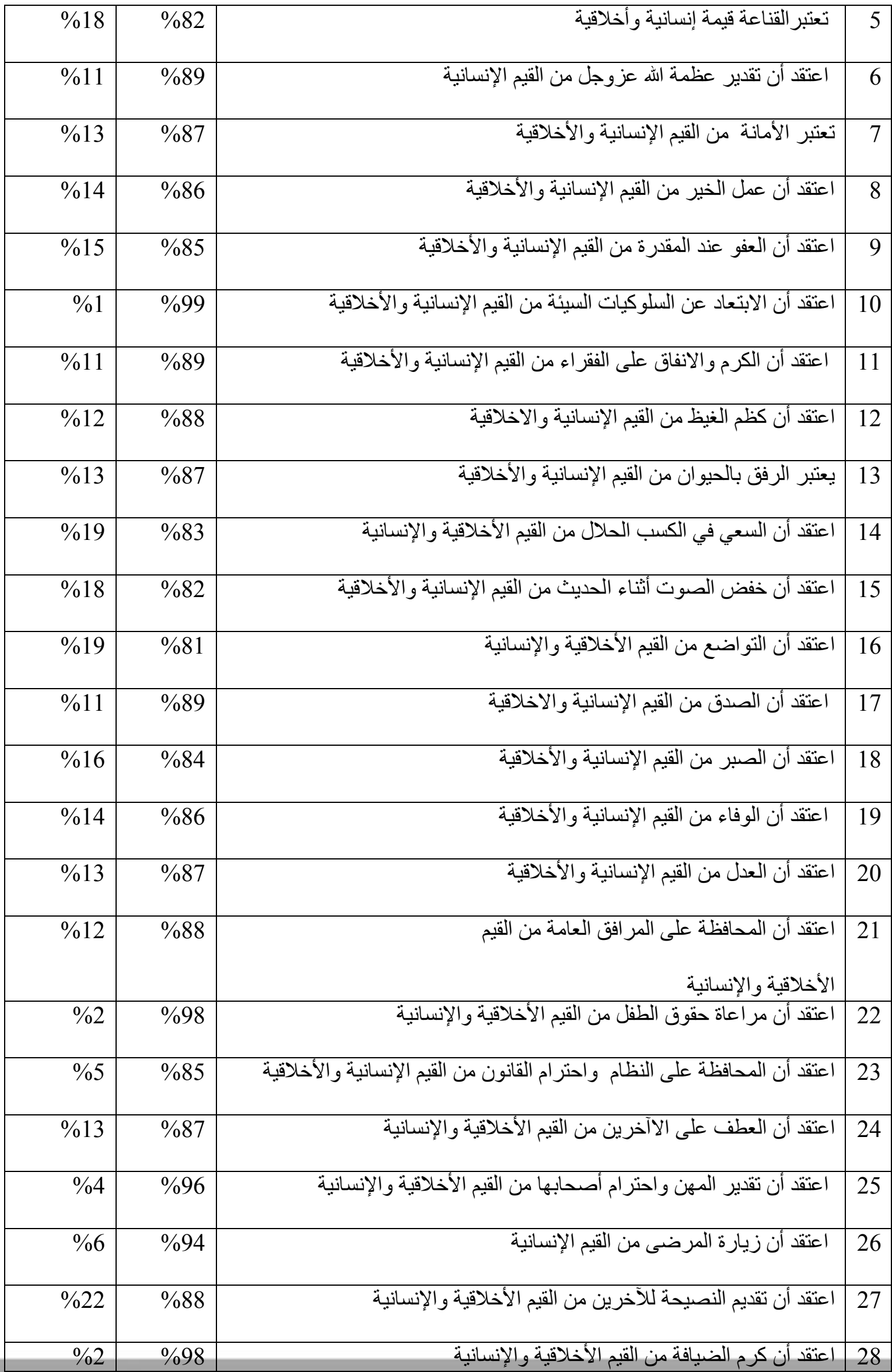

ARID International Journal of Social Sciences and Humanities (AIJSSH) 


\begin{tabular}{|c|c|c|c|}
\hline & & & \\
\hline$\% 1$ & $\% 99$ & الفيم الإسلسابيه و الا حدوبيه & 29 \\
\hline$\% 23$ & $\% 87$ & اعتقد أن ترشيد استخدام المياه والكهرباء من القيم الأخلاقية & 30 \\
\hline$\% 22$ & $\% 88$ & اعتقد أن حب المدرسة وتقدير المعلمين من القيم الأخلاقية & 31 \\
\hline$\% 11$ & $\% 89$ & اعتقد أن المحافظة على الأماكن المقدسة من القيم الأخلاقية و الإنسانية & 32 \\
\hline$\% 1$ & $\% 99$ & اعتقد أن حب الوطن و الدفاع عنه من القيم الإنسانية و الأخلاقية & 33 \\
\hline$\% 12$ & $\% 88$ & اعتقد أن حب الجمال مثل الفنون والاختر اعات من القيم الإنسانية & 34 \\
\hline
\end{tabular}

يتضح من الجدول السابق ما يلي: أن من 99\% إلى 82\% من عينة البحث قد اتفقو على القيم الإنسانية والأخلاقية التي يجب أن يتصف بها الأفراد في العالم المعاصر كالتالي: حب الوطن و الدفاع عنه، المحافظة على الأماكن المقدة، حب المدرسة وتقدير المعلمين، ترشيد استخدام المياه والكهرباء، تقدير التقدم العلمي، كرم الضيافة، تقديم النصيحة للآخرين، زيارة المرضى، تقدير المهن واحتر ام أصحابها، العطف على الآخرين، الحفاظ على النظام والحفاظ على القانوان واحترام حقوق الطفل، الرفق بالحيوان، العدل، الوفاء، الصبر، الصدق و التو اضع واحتر ام حقوق الغير، العطف على المساكين، الإيثار، الإخلاص في العمل، التسامح مع الآخرين، السعي في الكسب الحلال، كتم الغيظ، الرفق بالحيو ان، الكرم ، البعد عن السلوكيات السيئة، كتم الغيظ و عمل الخير، حب الجمال والفنون والاختر اعات، تقدير التقدم العلمي، تقديم النصيحة إلى الآخرين . السؤال الثالث:

للإجابة على السؤال الثالث: هل توجد علاقة بين السمات الثخصية للنبي محمد "صلى الله علية وسلم" والقيم الأخلاقية والإنسانية في العالم المعاصر؟ تم استخدام معاملات الارتباط و هو معامل ارتباط بيرسون

جدول(8): يوضح نتائج معاملات الارتباط بين سمات النبي محمد"صلى الله عليه وسلم" والقيم الأخلاقية والإنسانية

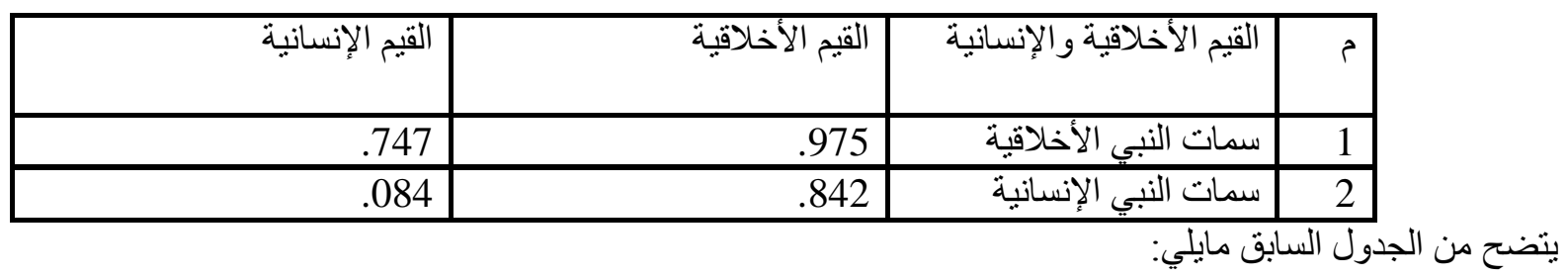

وجود ارتباط موجب دال احصائيا عند مستوى (01.) بين سمات النبي الأخلاقية والقيم الأخلاقية و القيم الإنسانية وكذلك وجود ارتباط موجب دال احصائيا عند (01. ) بين سمات النبي الإنسانية والقيم الأخلاقية والقيم الإنسانية، واتضح من خلال نتائج السؤال السابق أن 
هناك علاقة وثيقة الصلة وقوية جدا بين السمات الخلقية و الإنسانية للنبي محمد والقيم الأخلاقية والإنسانية التي يقدر ها جميع شعوب العالم من هنا يمكننا القول أن النبي محمد عليه السلام كانت رسالتة سامية وكان نبي رحمة للعالمين، وجاء بتعاليم وقيم سمحة ونادى بها وأنه شخصية عظيمة بشهادة علماء غربيون ومن ديانات أخرى غير الإسلام مثل بحث (عدنان خطاطبة,2015) حيث هدف البحث التعرف على القضايا المتضمنة في عملية اتصال النبي محمد عليه الصلاة والسلام بفئة المرضى و التعامل معهم في العالم المعاصر ، حيث انطوى هذا البحث على ما تضمنته سيرة النبي من قيم اجتماعية وصحية وبيئية من حيث زيارة للمرضى وما تنطوي عليه من قيم وجدانية وسلوكية وإرشادية، نرشد الناس في العالم المعاصر وما يفعلونه من قيم إنسانية في زيارة المرضى. 
[1] [حمد حسن و غلام حسن(2016). النبى الاعظم, ط1, : جدة , دار الكفيل للنشرو التوزيع و الطباعة.

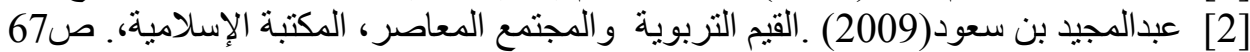

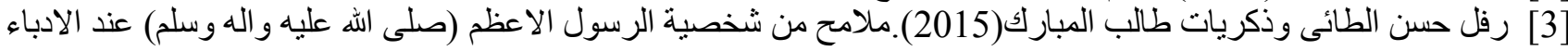

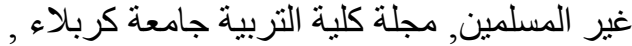

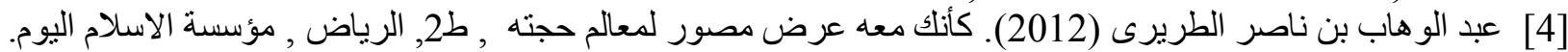

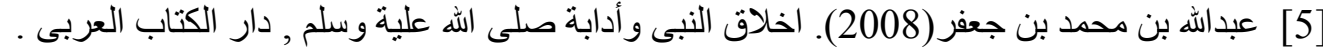

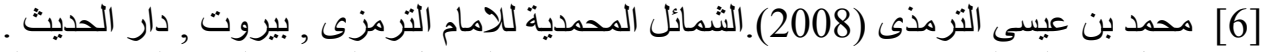
[7] ] عادل بن على الثدى (2019). 20جو هرة من اخلاق الرسول صلى الله عليه وسلم ,جامعة الملك سعود . .

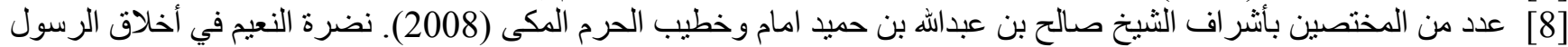

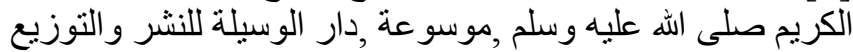

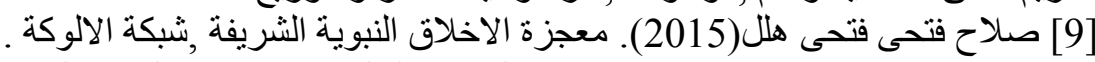

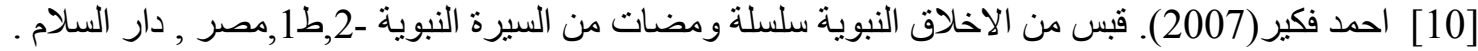

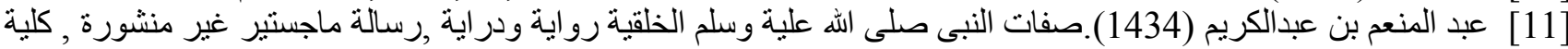

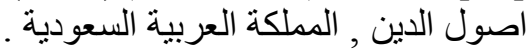

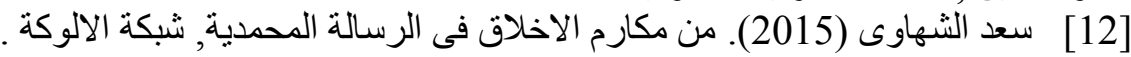

[13] عبدالفتاح محمود ادريس (254) (2016). القيم الاخلاقية ودور ها فى بناء المجتمع ,مجلة البحوث و الدر اسات الثر عية , مج6,ع 56.

.254-229,

[14] محمد امين الحق (2542).القيم الاسلامية فى التعليم و انثار ها على المجتمع , مجلة در اسات اسلامية , مجلد9, ص 344-335.

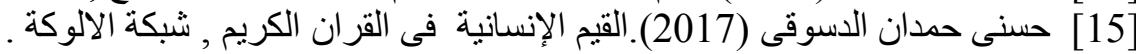

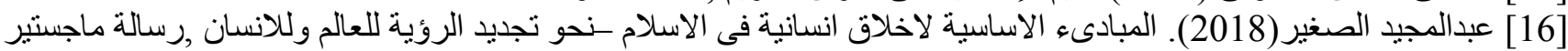

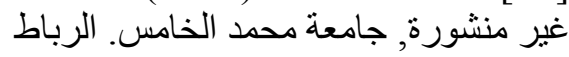

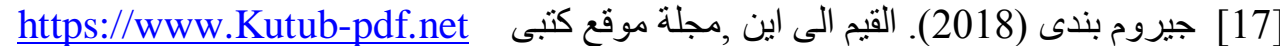

[18] [نادية محمود وسيف الدين واخرون (2018).

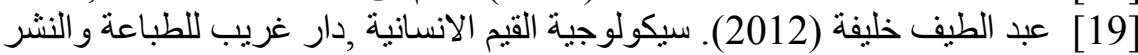

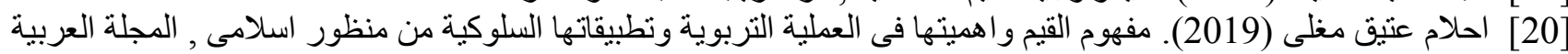

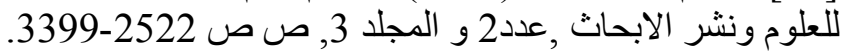

